\title{
The Relationship Between Antioxidant Enzymes and Lipid Peroxidation in Senescent Rat Erythrocytes
}

\author{
M. MLADENOV ${ }^{1}$, M. GOKIK ${ }^{1}$, N. HADZI-PETRUSHEV ${ }^{1}$, I. GJORGOSKI ${ }^{1}$, \\ N. JANKULOVSKI ${ }^{2}$
}

${ }^{1}$ Faculty of Natural Sciences and Mathematics, Institute of Biology, "Sts, Cyril and Methodius" University, Skopje, Macedonia, ${ }^{2}$ Faculty of Medical Sciences, "Sts, Cyril and Methodius" University, Skopje, Macedonia

Received August 5, 2014

Accepted February 20, 2015

On-line June 5, 2015

\section{Summary}

The aim of this study was to gain more complete information about the relationships between some endogenous antioxidants and the malondialdehyde (MDA) as a marker of lipid peroxidation, during $\mathrm{D}$-galactose induced senescence. The activities of superoxide dismutase (SOD), glutathione peroxidase (GPx), catalase (CAT) and the concentrations of uric acid (UA) in plasma and MDA in erythrocyte's hemolysate, were determined in 15 D-galactose (D-gal), treated rats and compared with 15 placebo. The activity of the erythrocyte's CAT was found significantly increased due to the senescence. The ratio of the activities of antioxidant enzymes $\mathrm{R}=\mathrm{SOD} /(\mathrm{GPx}+\mathrm{CAT})$ was significantly decreased due to the senescence and negatively correlated with the MDA ( $\rho=-0.524, p=0.045)$. The antioxidant enzymes SOD and GPx negatively correlated with the MDA, while CAT displayed no correlation. Further, the UA positively correlated with the ratio of activities of the antioxidant enzymes $\mathrm{R}=\mathrm{SOD} /(\mathrm{GPx}+\mathrm{CAT}), \quad(p=0.564, \mathrm{p}=0.029$ for senescent rats $)$. Obtained results may contribute to better understanding of the process of D-gal induced senescence in the erythrocytes.

\section{Key words}

D-galactose • Antioxidant enzymes • Uric acid • Malondialdehyde - Rats

\section{Corresponding author}

M. Mladenov, Faculty of Natural Sciences and Mathematics, Institute of Biology, "Sts, Cyril and Methodius" University, P.O. Box 162, Skopje 1000, Macedonia. Fax: +389 23228141. E-mail: mitkom@pmf.ukim.mk

\section{Introduction}

A wide variety of factors can influence the activities of the antioxidant enzymes. In relation to "free radical theory of aging", special attention has been given to the alteration of the antioxidant activity during aging (Wei et al. 2005). However, conflicting results do exist and association between antioxidant status, lipid peroxidation and aging, seem to display variations depending on the examined system (Rikans and Hornbrook 1997).

A process very similar to the natural aging can be induced by chronic administration of D-gal. The rodents treated with D-gal can be used as an animal model for oxidative stress (Ho et al. 2003, HadziPetrushev et al. 2014). The process is based on one of the proposed mechanisms of D-gal induced senescence, known to involve increased production of superoxide anions, changes in antioxidant enzyme activities and accumulation of oxidative damages (He et al. 2009, Wei et al. 2005). Such an increased generation of superoxide radicals, may cause extensive damage of the erythrocyte membranes, due to the induced membrane protein oxidation and lipid peroxidation measured through a production of the malondialdehyde (MDA) (Yelinova et al. 1996). On the other hand, the ameliorative mechanisms responsible for correction of the D-gal induced superoxide production, includes conversion to membrane-permeable hydrogen peroxide $\left(\mathrm{H}_{2} \mathrm{O}_{2}\right)$ by action of the superoxide dismutase (SOD), dominantly 
present in the intermembrane space as a $(\mathrm{Cu} / \mathrm{ZnSOD})$. The produced $\mathrm{H}_{2} \mathrm{O}_{2}$ can be reduced to water by glutathione peroxidase (GPx), using electrons from the glutathione (GSH) (Jaeschke 1990). The last reaction ends with oxidation of the GSH into glutathione disulfide (GSSG), as an index for increased $\mathrm{H}_{2} \mathrm{O}_{2}$ formation (Knight et al. 2001). Also, it is well known that despite GPx, the catalase (CAT), play a critical role in neutralization of the produced $\mathrm{H}_{2} \mathrm{O}_{2}$ (Jaeschke 1990). Conversely to the enzymatic, remarkable attention has been given to the non-enzymatic low molecular weight antioxidant (LMWA), uric acid (UA), which may work indirectly as an antioxidant through cooperation with the GSH (Goss et al. 1999). However, the relative contribution of this antioxidant player in the prevention of the oxidative damage on erythrocyte level, as a complementary onset during D-gal induced senescence is not yet examined. Based on that, together with our previous results (Hadzi-Petrushev et al. 2011, Stojkovski et al. 2013), that sensitivity to free radicals during the process of aging, depends on the equilibrium between the formation of $\mathrm{H}_{2} \mathrm{O}_{2}$ and its degradation, we hypothesized that the disequilibrium between the formation of $\mathrm{H}_{2} \mathrm{O}_{2}$ and its degradation, can be taken as a marker in the processes of development of oxidative stress on erythrocyte level, during D-gal induced senescence.

From all mentioned above, the aim of this study was to investigate the relationship between the ratio of activities of the antioxidant enzymes $\mathrm{R}=\mathrm{SOD} /(\mathrm{GP} x+\mathrm{CAT})$ and the levels of UA and MDA in erythrocytes of D-gal treated rats.

\section{Material and Methods}

\section{Animals and experimental design}

All experimental procedures were conducted in accordance with the Guiding Principles for Care and Use of Laboratory Animals approved by the Macedonian Center for Bioethics. All protocols were approved by the Animal Ethics Committee of the University "SS. Cyril and Methodius", Skopje, R. Macedonia, in accordance with the International Guiding Principles for Biomedical Research Involving Animals, as issued by the Council for the International Organizations of Medical Sciences. Anesthetics were applied according to the standards given by the guide of the EC Directive 86/609/EEC. Animals were anesthetized with an intraperitoneal injection of thiopental sodium (Rhone-Poulenc Rorer Limited, Nenagh, Co Tipperary, Ireland), $50 \mathrm{mg} \mathrm{kg}^{-1}$ b. wt. Male
Wistar rats $(n=30)$ on the age of 6 months were used for all protocols and were maintained on a 12:12 light : dark cycle and fed with standard rat chow and water ad libitum.

All animals were divided depending on the treatment with D-gal into: placebo $(P),(n=15)$, and D-gal treated (D-gal) rats, $(n=15)$. The rats in (D-gal) group were treated intra-gastrally with a water solution of D-gal (100 mg kg-1 b. wt) for 42 consecutive days. Previously, it was shown that the used dose of D-gal, induces senescence in the rats (Kumar and Rizvi 2014). The rats in the placebo group were treated intra-gastrally with $0.9 \%$ saline, $1.5 \mathrm{ml}$ daily, subcutaneous. During the period of treatment, all animals were housed at $22 \pm 2{ }^{\circ} \mathrm{C}$.

\section{Erythrocytes isolation}

The rat's venous blood samples (from an abdominal vein) were taken at 11:00 o'clock on the day of sacrifice. The heparinized $(25 \mathrm{U} / \mathrm{ml})$ fasting venous blood, was washed three times with a $0.15 \mathrm{~mol} / \mathrm{l} \mathrm{NaCl}$ solution. After the centrifugation $(400 \mathrm{~g}, 5 \mathrm{~min})$ the erythrocytes were hemolyzed by adding a triple volume of distilled water.

\section{Assay for SOD activity}

SOD activity was determined according to the method described by Marklund and Marklund (1974) based on the ability of SOD to inhibit the auto-oxidation of the pyrogallol. The reaction mixture consisted of $50 \mathrm{mM}$ Tris- $\mathrm{HCl}, \mathrm{pH} 8.2,1 \mathrm{mM}$ diethylenetriamine pentaacetic acid and sample. The reaction was initiated by addition of pyrogallol (final concentration of $0.2 \mathrm{mM}$ ) and the absorbance was measured kinetically at $420 \mathrm{~nm}$, $25^{\circ} \mathrm{C}$, for $3 \mathrm{~min}$. One unit of activity was defined as an amount of sample needed to inhibit the pyrogallol oxidation by $50 \%$. Final results were expressed as U/g hemoglobin.

\section{Assay for CAT activity}

The CAT activity was determined by measuring the degradation of $\mathrm{H}_{2} \mathrm{O}_{2}$ using the method described by Claiborne (1985). The reaction mixture $(1 \mathrm{ml})$ consisted of $50 \mathrm{mM}$ potassium phosphate buffer, $\mathrm{pH} 7.0,19 \mathrm{mM}$ $\mathrm{H}_{2} \mathrm{O}_{2}$ and an appropriate volume of sample. The reaction was initiated by addition of $\mathrm{H}_{2} \mathrm{O}_{2}$ and the changes in the absorbance was followed at $240 \mathrm{~nm}, 25^{\circ} \mathrm{C}$, for a time period of $30 \mathrm{~s}$, taking measurements at $5 \mathrm{~s}$ intervals. In these conditions, the molar extinction coefficient for $\mathrm{H}_{2} \mathrm{O}_{2}$ is $43.6 \mathrm{M}^{-1} \mathrm{~cm}^{-1}$. The activity of CAT was 
expressed as U/g hemoglobin, with one unit of activity being equal to the conversion of $1 \mu \mathrm{mol} \mathrm{H}_{2} \mathrm{O}_{2}$ per minute.

\section{Assay for GPx activity}

The GPx activity was determined according to the method described by Lawrence and Burk (1976). The activity was assayed by following the oxidation of $\mathrm{NADPH}$ at $340 \mathrm{~nm}$ for $3 \mathrm{~min}, 25{ }^{\circ} \mathrm{C}$, in presence of GR and GSH. The reaction mixtures containing $50 \mathrm{mM}$ potassium phosphate, $\mathrm{pH} 7.0,1 \mathrm{mM}$ sodium azide, $2 \mathrm{mM}$ GSH, $0.2 \mathrm{mM}$ NADPH, $1 \mathrm{U} / \mathrm{ml}$ GR, $1.5 \mathrm{mM}$ cumene hydroperoxide and sample were incubated at $25^{\circ} \mathrm{C}$ for $5 \mathrm{~min}$. The reaction was initiated by addition of cumene hydroperoxide. One unit of activity was defined as oxidation of $1 \mu \mathrm{mol}$ NADPH per minute. The final results were expressed as $\mathrm{U} / \mathrm{g}$ hemoglobin.

\section{Uric acid assay}

Plasma levels of UA were measured using clinical chemistry analyzer Cobas Integra 400 plus (Thermo Fisher Scientific Inc., USA) according to the manufacturer's instructions.

\section{Malondialdehyde assay}

The lipid peroxides were estimated in erythrocyte's hemolysate by using the thiobarbituric acid (TBA) reactive substances tests, described by Ohkawa et al. (1979). After addition of $8.1 \%$ sodium dodecyl sulfate, each sample or standard (1,1,3,3tetraethoxypropane solution) was vortexed and left at room temperature for $10 \mathrm{~min}$. At the end of the incubation period, $20 \%$ acetic acid and $0.6 \%$ thiobarbituric acid was added and the test tubes were placed in a water bath at $90-95{ }^{\circ} \mathrm{C}$ for $1 \mathrm{~h}$. After that, they were cooled on ice and colored supernatant was obtained by adding a mixture of butanol : pyridine (15:1), vortexing and centrifuging. The absorbance was measured at $535 \mathrm{~nm}$. The results were expressed as $\mu \mathrm{mol}$ MDA per $\mathrm{g}$ hemoglobin.

The analyses of the MnSOD, GPx, and GR were carried out on ELISA reader (Bio-Rad). The hemoglobin $\mathrm{Hb}$ concentration in the hemolysate was measured using the Drabkin method.

\section{Statistical analysis}

The data were analyzed by one-way ANOVA, followed by the Newman-Keulls multiple comparison test between all groups. The correlation between different parameters was assessed by Spearman's test. Only 2-tailed probabilities were used for testing statistical significance. Probability values $<0.05$ were regarded as statistically significant. All analyses were performed with Graph Pad Prism 4.0 (San Diego, CA, USA).

Table 1. Biochemical characteristics of animals.

\begin{tabular}{|c|c|c|c|}
\hline$*$ & Placebo $($ Mean \pm SEM) & D-gal $($ Mean \pm SEM) & $\mathbf{p}$ \\
\hline$S O D(U / g H b)$ & $501.376 \pm 32.50$ & $285.805 \pm 18.194$ & $<0.001$ \\
\hline$G P x(U / g H b)$ & $37.524 \pm 0.42$ & $19.890 \pm 0.657$ & $<0.001$ \\
\hline$C A T(U / g H b)$ & $19158.67 \pm 3228.77$ & $25742 \pm 3780.432$ & $<0.05$ \\
\hline$M D A(\mu m o l / g ~ H b)$ & $0.0142 \pm 0.0017$ & $0.0715 \pm 0.0065$ & $<0.001$ \\
\hline$R$ (erythrocytes) & $0.04 \pm 0.007$ & $0.014 \pm 0.004$ & $<0.001$ \\
\hline Uric acid (mg/dl) & $5.874 \pm 0.996$ & $4.891 \pm 0.931$ & $<0.05$ \\
\hline
\end{tabular}

Significance levels $\mathrm{p}$ between-groups (controls versus D-gal). Comparisons were made using the Newman-Keulls multiple comparison tests between all groups. Data are given as Mean $\pm \mathrm{SEM}, \mathrm{R}=\mathrm{SOD} /(\mathrm{GPx}+\mathrm{CAT})$ (activities of enzymes in erythrocytes).

\section{Results}

The activities of antioxidant enzymes (SOD, GPx and CAT) in the erythrocytes of the senescent and placebo rats are shown in (Table 1). The changes in the equilibrium between the formation of hydrogen peroxide by superoxide dismutation and its decomposition by the
GPx and CAT in erythrocytes, are expressed by the ratio $\mathrm{R}=\mathrm{SOD} /(\mathrm{GPx}+\mathrm{CAT})$. This ratio is significantly different in senescent when compared to the placebo erythrocytes $(0.040 \pm 0.007$ versus placebos $0.015 \pm 0.004 ; \mathrm{p}<0.001)$. The UA, as a basic non-enzymatic antioxidant in our experiments, was significantly decreased as a consequence of the senescence $(5.01 \pm 0.36 \mathrm{mg} / \mathrm{dl}$ versus 
placebos $\quad 6.253 \pm 0.52 \mathrm{mg} / \mathrm{dl} ; \quad \mathrm{p}<0.05$ ) $\quad$ (Table 1). The concentration of the lipid peroxidation product, the erythrocyte's MDA, show significant differences between both tested groups $(0.072 \pm 0.006 \mu \mathrm{mol} / \mathrm{g} \mathrm{Hb}$ versus placebo $0.014 \pm 0.002 \mu \mathrm{mol} / \mathrm{gHb} ; \quad \mathrm{p}<0.001)$. In the senescent erythrocytes no significant correlation between the MDA and the CAT activity was observed, except the negative correlation between the MDA and the antioxidant enzymes SOD $(\rho=-0.579, p=0.024)$ and GPx $(\rho=-0.521, p=0.046)$ (Figs 1A and 1B, respectively). The negative correlation between the ratio R and MDA in the senescent erythrocytes is shown in Figure 1C $(\rho=-0.524$, $\mathrm{p}=0.045$ ). A significant positive correlations were observed between the UA in the plasma and the SOD and $R$ in the senescent erythrocytes $(\rho=0.564, p=0.029$ and $\rho=0.511, p=0.041$; Figs $1 \mathrm{D}$ and $1 \mathrm{E}$, respectively). According to our expectation, the senescent MDA negatively correlated with the UA from the senescent erythrocytes $(\rho=-0.568, p=0.027)$ (Fig. 1F).
A
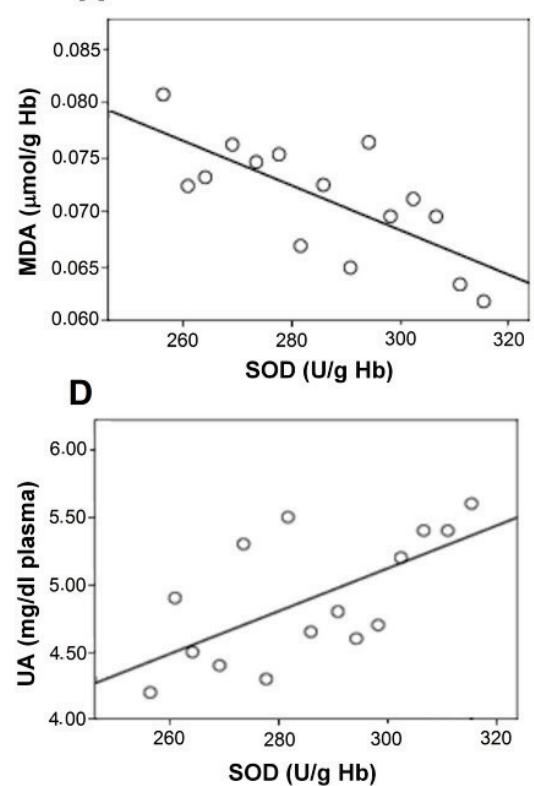

B

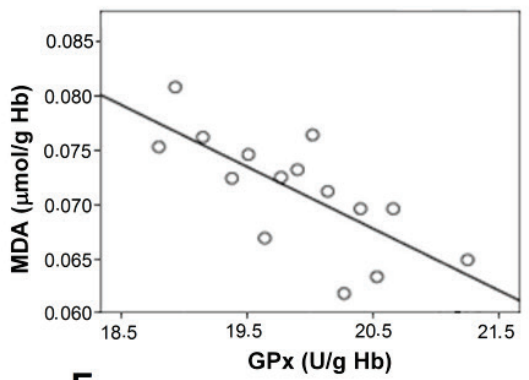

E

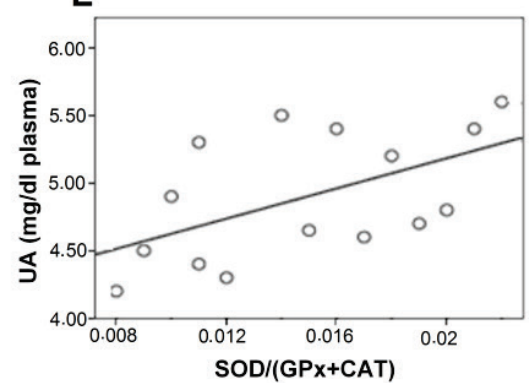

C
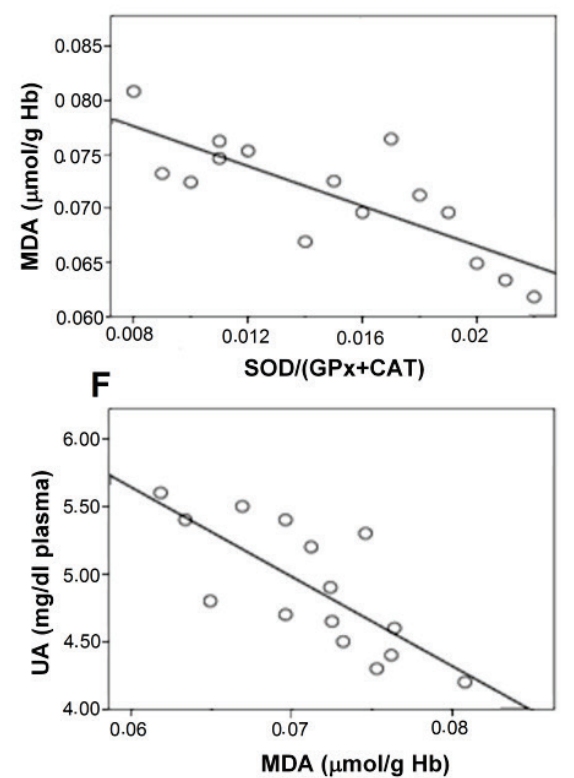

Fig. 1. A. Correlation between SOD activity and MDA level in senescent erythrocytes $(\rho=-0.579, p=0.024, n=15)$. B. Correlation between GPx activity and MDA level in senescent erythrocytes $(\rho=-0.521, p=0.046, n=15)$. C. Correlation between the ratio $\mathrm{R}=\mathrm{SOD} /(\mathrm{GPx}+\mathrm{CAT})$ (activities of enzymes) and MDA level in senescent erythrocytes $(\rho=-0.524, p=0.044, n=15)$. D. Correlation between erythrocyte SOD activity and UA in the plasma of senescent rats $(\rho=0.511, p=0.039, n=15)$. E. Correlation between the ratio $\mathrm{R}=\mathrm{SOD} /(\mathrm{GPx}+\mathrm{CAT})$ (activities of enzymes) and UA in the plasma of senescent rats $(\rho=0.564, p=0.029, n=15)$. F. Correlation between MDA levels in senescent erythrocytes and UA in the plasma of senescent rats $(\rho=-0.568, p=0.027)$.

\section{Discussion}

Here we have shown that disequilibrium in the antioxidant enzymes from the senescent erythrocytes is partly in accordance with the detected disequilibrium in the different settings from our previous studies (HadziPetrushev et al. 2011, 2014, Stojkovski et al. 2013). In the same direction, Coban et al. (2014) reported that decreased SOD activity in the liver of senescent rats is not compensated by the changes in the GPx activity. Further, Amstad et al. (1991) published that the epidermal cells with an overproduction of the SOD, are very sensitive to superoxide and hydrogen peroxide, whereas the cells with an overproduction of the CAT, are protected against the effects of the oxidants. Such a protective effect of CAT was also confirmed in our study, as we found a significant increase of its activity in the senescent erythrocytes. Also, we observed an inverse relationship between the decreased ratio $\mathrm{R}=\mathrm{SOD} /(\mathrm{GPx}+\mathrm{CAT})$ and increased lipid peroxidative marker MDA in the senescent erythrocytes. These results may support the theory of contribution of the antioxidant enzymes disequilibrium to oxidative stress in senescent erythrocytes. Moreover, a fivefold increase of the erythrocyte MDA during the senescence, found in this study, additionally support our hypothesis that the balance of oxygen metabolism is compromised at erythrocyte level. 
Taking into account that oxidative stress may reflect changes in the LMWA systems (Chung and Yu 2000), our results suggest that the failure of the erythrocyte antioxidant enzyme system led to failure in the metabolism of the LMWA systems. The positive correlation between the $\mathrm{R}$ and UA, indicate for an exhaustion of the UA during the senescence, initiated by an imbalance in the activities of antioxidant enzymes, SOD versus GPx and CAT. In the same direction, the positive correlation between SOD and UA indicate that the reducing ability of the UA is associated with the catalytic SOD activity (Garaiova et al. 2004, Žitnanova et al. 2004). Precisely, this is in agreement with the fact that during the dismutation of $\mathrm{O}_{2}^{-}$to $\mathrm{H}_{2} \mathrm{O}_{2}$, the SOD can be inactivated (Hink et al. 2002, Jewett et al. 1999). Nevertheless, such an inactivation of SOD might be prevented in presence of small anions of the UA, as a result of their reducing ability (Goss et al. 1999). Further, if the UA work indirectly as an antioxidant through cooperation with the GSH, then from the electrochemical potentials for $\mathrm{GS}^{\bullet} / \mathrm{GS}^{-}(+0.85 \mathrm{~V})$, (Mladenov et al. 2004) and for urate radical/urate $(+0.52 \mathrm{~V})$ (Buetnner and Jurkiewicz 1993), arises that UA has ability to regenerate the GSH from GSH radical. This indicates that improvement of erythrocyte's GSH/GSSG ratio could be of possible therapeutic value in the treatment of the senescence. In addition, this is corroborated by numerous studies related to improvement of the natural aging state as a result of the improvement of the GSH/GSSG ratio (Hadzi-Petrushev et al. 2011).

In summary, the careful evaluation of parameters representing the oxidative stress in senescent rat erythrocytes and their relationship to the reparatory mechanisms may contribute to better understanding of senescence inducing mechanisms, suggesting the beneficial role of adequate antioxidant therapy. As far as the relevance of these findings in rodents to the humans, this could be another important area for future comparative investigation.

\section{Conflict of Interest}

There is no conflict of interest.

\section{Acknowledgements}

This research project was supported by grant of University "Sts Cyril and Methodius" Program (003-2013). This work was also supported by the University of Zurich.

\section{Abbreviations}

D-gal, D-galactose; CAT, catalase; GPx, glutathione peroxidase; MDA, malondialdehyde; SOD, superoxide dismutase.

\section{References}

AMSTAD P, PESKIN A, SHAH, G, MIRAULT ME, MORET R, ZBINDEN I, CERUTTI P: The balance between $\mathrm{Cu}, \mathrm{Zn}$-superoxide dismutase and catalase affects the sensitivity of mouse epidermal cells to oxidative stress. Biochemistry 30: 9305-9313, 1991.

BUETTNER GR, JURKIEWICZ BA: Ascorbate free radicals as a marker of oxidative stress: an EPR study. Free Radic Biol Med 14: 49-55, 1993.

CHUNG HY, YU BP: Significance of hepatic xanthine oxidase and uric acid in aged and dietary restricted rats. $J A m$ Aging Assoc 23: 123-128, 2000.

CLAIBORNE A: Catalase activity. In: CRC Handbook of Methods for Oxygen Radical Research. GREENWALD RA (ed.), CRC Press, Boca Raton, FL, USA, 1985, pp 283-284.

COBAN J, BETUL-KALAZ E, KUCUKGERGIN C, AYDIN AF, DOGAN-EKICI, I, DOGRU-ABBASOGLU S, UYSAL M: Blueberry treatment attenuates D-galactose-induced oxidative stress and tissue damage in rat liver. Geriatr Gerontol Int 14: 490-497, 2014.

GARAIOVA I, MUCHOVA J, ŠUSTROVA M, BLAZICEK P, SIVONOVA M, KVASNICKA P, PUESCHEL S, ĎURACKOVA Z: The relationship between antioxidant systems and some markers of oxidative stress in persons with Down syndrome. Biologia 59: 787-794, 2004.

GOSS SPA, SINGH RJB, KALYANARAMAN B: Bicarbonate enhances the peroxidase activity of Cu,Zn-superoxide dismutase. Role of carbonate anion radical. J Biol Chem 274: 28233-28239, 1999. 
HADZI-PETRUSHEV N, JANKULOVSKI N, HRISTOV K, MLADENOV M: L-2-oxothiazolidine-4-carboxylate influence on age- and heat exposure-dependent redox changes in rat's blood plasma. J Physiol Sci 61: 437-442, 2011.

HADZI-PETRUSHEV N, STOJKOVSKI V, MITROV D, MLADENOV M: D-galactose induced inflammation lipid peroxidation and platelet activation in rats. Cytokine 69: 150-153, 2014.

HADZI-PETRUSHEV N, STOJKOVSKI V, MITROV D, MLADENOV M: D-galactose induced changes in enzymatic antioxidant status in rats of different ages. Physiol Res 64: 61-70, 2015.

HE M, ZHAO L, WEI MJ, YAO WF, ZHAO HS, CHEN FJ: Neuroprotective effects of -epigallocatechin-3-gallate on aging mice induced by D-galactose. Biol Pharm Bull 32: 55-60, 2009.

HO SC, LIU JH, WU RY: Establishment of the mimetic aging effect in mice caused by D-galactose. Biogerontology 4 : 15-18, 2003.

HINK HU, SANTANAM N, DIKALOV S, MCCANN L, NGUYEN AD, PARTHASARATY S, HARRISON DG, FUKAI T: Peroxidase properties of extracellular superoxide dismutase. Role of uric acid in modulating in vivo activity. Arterioscler Thromb Vasc Biol 22: 1402-1408, 2002.

JAESCHKE H: Glutathione disulfide formation and oxidant stress during acetaminophen-induced hepatotoxicity in mice in vivo: The protective effect of allopurinol. J Pharmacol Exp Ther 255: 935-941, 1990.

JEWETT SL, ROCKLIN AM, GHANEVATI M, ABEL JM, MARACH JA: A new look at a Timeworn system: oxidation of CuZn-SOD by $\mathrm{H}_{2} \mathrm{O}_{2}$. Free Radic Biol Med 26: 905-918, 1999.

KNIGHT TR, KURTZ A, BAJT ML, HINSON JA, JAESCHKE H: Vascular and hepatocellular peroxynitrite formation during acetaminophen induced liver injury: role of mitochondrial oxidant stress. Toxicol Sci 62: 212-220, 2001.

KUMAR D, RIZVI SI: Plasma paraoxonase 1 arylesterase activity in D-galactose-induced aged rat model: correlation with LDL oxidation and redox status. Aging Clin Exp Res 26: 261-267, 2014.

LAWRENCE RA, BURK RF: Glutathione peroxidase activity in selenium deficient rat liver. Biochem Biophys Res Commun 71: 952-958, 1976.

MARKLUND S, MARKLUND G: Involvement of superoxide anion radical in the autoxidation of pyrogallol and a convenient assay for superoxide dismutase. Eur J Biochem 47: 469-474, 1974.

MLADENOV M, MIRCESKI V, GJORGOSKI I, JORDANOSKI B: Redox kinetic measurements of glutathione at the mercury electrode by means of square-wave voltammetry. The role of copper, cadmium and zinc ions. Bioelectrochemistry 65: 69-76, 2004.

OHKAWA H, OHISHI N, YAGI K: Assay for lipid peroxides in animal tissue by thiobarbituric acid reaction. Anal Biochem 95: 351-358, 1979.

RIKANS LE, HORNBROOK KR: Lipid peroxidation, antioxidant protection and aging. Biochim Biophys Acta 1362: 116-127, 1997.

STOJKOVSKI V, HADZI-PETRUSHEV N, ILIESKI V, SOPI R, GJORGOSKI I, MITROV D, JANKULOVSKI N, MLADENOV M: Age and heat exposure-dependent changes in antioxidant enzymes activities in rat's liver and brain mitochondria: role of $\alpha$-tocopherol. Physiol Res 62: 503-510, 2013.

WEI H, LI L, SONG Q, AI H, CHU J, LI W: Behavioral study of the D-galactose induced aging model in C57BL/6J mice. Behav Brain Res 157: 245-251, 2005.

YELINOVA V, GLAZACHEV Y, KHRAMTSOV V, KUDRYASHOVA L, RYKOVA V, SALGANI R: Studies of human and rat blood under oxidative stress: changes in plasma thiol level, antioxidant enzyme activity, protein carbonyl content, and fluidity of erythrocyte membrane. Biochem Biophys Res Commun 221: 300-303, 1996.

ŽITŇANOVÁ I, KORYTÁR P, ARUOMA IA, ŠUSTROVÁ M, GARAIOVÁ I, MUCHOVÁ J, K ALNOVIČOVÁ T, PUESCHEL S, ĎURAČKOVÁ Z: Uric acid and allantoin levels in Down syndrome: antioxidant and oxidative stress mechanisms. Clin Chim Acta 341: 139-146, 2004. 